\title{
Voice changes associated with inhaled steroids In obstructive lung disease patients
}

\begin{abstract}
Background/Aims: The widespread use of inhaled corticosteroids (ICS) for the treatment of obstructive lung disease may be associated with both systemic and local side effects. These local side effects; including voice problems, oropharyngeal candidiasis, throat clearing, sense of fullness, pharyngitis, and cough, are generally viewed as minor complications of therapy in what is called steroid inhaler laryngitis (SIL). Few studies have been performed to specifically evaluate local side effects of ICS. However, they can be clinically significant, affect patient's quality of life, hinder compliance with therapy, and mask symptoms of more serious disease. The aim of this study is to examine the effect of ICS on the larynx and subsequent voice changes, and highlighting if these voice problems related to the type of inhaled corticosteroids in order to determine the importance of regular laryngeal examination in those patients.
\end{abstract}

Methods: 40patients with bronchial asthma and 40 patients with COPD admitted to Chest department in Menoufia and Zagazig University Hospitals during the period from March 2017 to March 2019 were included in the study. They were divided according to the type of cortisone used into four groups; group (I): beclomethasone dipropionate (BDP) users, group (II): budesonide (BUD) users, group (III): Ciclesonide users and group (IV): fluticasone propionate (FP) users. They were evaluated as regards videolaryngoscopic examination and acoustic analysis

Results: The age of the patients with bronchial asthma ranged from 29 to 42 years and the age of the patients with COPD ranged from 31 to 43years. There was a statistically significant difference among the four groups of cortisone inhalation regarding laryngoscopic findings; as presence of congestion (diffuse and local), mucus spills on VF and glottis gap were all higher in frequency among the group of patients used fluticasone FP, while least signs found among ciclesonide users. Also, average pitch, Jitter, $\mathrm{H} / \mathrm{N}$ ratio and MPT were more worsen in fluticasone group when compared with Ciclesonide group.

Conclusion: obstructive lung disease patients may suffer from voice problems related to the type of inhaled corticosteroids that could be fade when therapy is stopped. So, regular laryngeal examination in those patients is important.

Keywords: voice changes, inhaled corticosteroids, obstructive lung disease, steroid inhaler laryngitis
Volume I2 Issue I - 2020

\author{
Baraka M,' Hossam EIDessouky, ${ }^{2}$ Ahmed \\ Amer Khamees, ${ }^{3}$ Ayman Ali Abd ElFattah, ${ }^{4}$ \\ Eman Ezzat, ${ }^{5}$ Nasser Labeb Elnakeb ${ }^{6}$ \\ 'Department of Oto Rhino Laryngology, Phoniatric Unite, Ain \\ Shams University, Egypt \\ ${ }^{2}$ Department of Oto Rhino Laryngology, Phoniatric Unite, Cairo \\ University, Egypt \\ ${ }^{3}$ Department of Chest Diseases, Menoufia University, Egypt \\ ${ }^{4}$ Department of Oto Rhino Laryngology, Menoufia University, \\ Egypt \\ ${ }^{5}$ Department of Oto Rhino Laryngology, Phoniatric Unite, \\ Menoufia University, Egypt \\ ${ }^{6}$ Department of Oto Rhino Laryngology, Phoniatric Unite, \\ Zagazig University, Egypt
}

Correspondence: Eman Ezzat Abd El-Wahed Ismail, Faculty of Medicine, Department of Oto-Rhino Laryngology, Menoufia University, Menoufia, Egypt, Tel +2-01007I06778, Fax 002-0482222303,Email emezzat50@yahoo.com

Received: September 25, 2019 | Published: January 02, 2020
Abbreviation: COPD, chronic obstructive pulmonary disease; ICS, inhaled corticosteroids; SIL, steroid inhaler laryngitis; BDP, beclomethasone dipropionate; FP, fluticasone propionate

\section{Introduction}

Chronic obstructive pulmonary disease (COPD) is responsible for early mortality, high death rates and significant cost to health systems. It is the 12th leading cause of years lost through early mortality or handicap in 1990. Prevalence of COPD varies according to country, age, and sex. ${ }^{1}$ COPD impacts life in many ways. Frequent wheezing and coughing, trouble breathing, coughing up mucus, and shortness of breath are just a few COPD symptoms. According to the American Speech-Language-Hearing Association, these and other COPD symptoms can cause harmful effect on the throat and vocal folds, causing problems like voice, communication and swallowing disorders. Voice changes are not a direct symptom of COPD, but many COPD patients experience voice changes due to COPD symptoms and even certain COPD medications. ${ }^{2}$ Asthma is a chronic inflammatory disorder of the airways that causes recurrent episodes of coughing, wheezing, breathlessness, and chest tightness. These episodes are usually associated with variable airflow obstruction that is often reversible, either spontaneously or with treatment. The worldwide prevalence of asthma is estimated to be approximately 300 million, and it is expected to increase by $33 \%$ to 400 million by $2025 .^{3}$ Inhaled corticosteroids have been used in the treatment of COPD and asthma for many years. The use of these inhaled drugs has significantly decreased the systemic side effects of corticosteroids. ${ }^{4}$

Local side effects are the most frequent adverse effects associated with inhaled corticosteroids (ICS) use. Most frequently seen local side effects of ICS are dysphonia. The incidence of dysphonia upon corticosteroid inhalation is approximately $1 \%$ to $8 \%$ with increasing frequency at higher doses. ${ }^{5}$ Other clinical studies had reported that dysphonia with inhaled steroids is as high as $55 \%{ }^{6}$, oropharyngeal candidiasis $(1-4 \%)$, and throat irritation $(1-4 \%)^{5}$. ICS-induced 
laryngitis may be a form of chemical irritation that have laryngeal findings ranging from mucosal edema, erythema and thickening to leukoplakia, granulation, and candidiasis. ${ }^{6}$ Dysphonia may arise from organic disorders, non-organic (functional) voice disorders, or minimal associated pathological lesions. One of the causes of organic dysphonia is the chemical injury to the larynx, especially in obstructive lung disease patients (COPD and asthma) who are being treated with ICS 7 . This type of dysphonia is not responsive to treatment of other causes of dysphonia, but improves with cessation of inhaled steroid therapy. ${ }^{5}$ Lavy et al., ${ }^{7}$ had found a mixture of causes for dysphonia associated with inhaled steroids including bowing, mucosal changes, and hyperfunction. They thought that bowing could have been caused by either myopathy or mucosal atrophy. The mucosal changes were due either to a direct steroid effect on the mucosa, a steroid or propellant effect on the mucus lying mucosa, or a steroid or propellant effect on the mucus-secreting glands in the ventricles and the trachea. They postulate that the hyperfunction dysphonia could be either a musculoskeletal adaptation to the laryngeal mucosal changes or to the underlying poor pulmonary reserve. ${ }^{8}$ Acar et al., ${ }^{9}$ had found a significant correlation between duration of ICS treatment and its doses on one side, and pathological changes in the larynx on the other side. They thought that it was impossible to provide a typical dosage and treatment duration which can be considered to be safe for the larynx, because minimal steroid doses or even only one-month duration of steroid usage may cause symptoms. In some cases, vocal fold (VF) changes were severe enough to prompt direct laryngoscope and biopsy. ${ }^{5}$

\section{Patients and methods}

\section{Patients}

This study is a prospective study that was applied on 40 patients with bronchial asthma and 40 patients with COPD who were recruited from those admitted to Chest department in Menoufia and Zagazig University Hospitals during the period from March 2017 to March 2019 (the sample was on convenience). The purpose and method of the study was explained to the patient that had given their written informed consent using appropriate language including study title, purpose of the study, study procedures, benefits, risks, right to refuse, and signature. Subjects were evaluated for inclusion by chest disease specialists of experience not less than ten years based on radiological evaluation (X-ray and CT scan) and pulmonary function test using Spirometer. Patients were divided according to type of cortisone used into four groups; group (I): beclomethasone dipropionate (BDP) users [13 COPD and $7 \mathrm{BA}$ ], group (II): budesonide (BUD) users [9 COPD and $11 \mathrm{BA}$ ], group (III): Ciclesonide users [6 COPD and $14 \mathrm{BA}$ ], and group (IV): fluticasone propionate (FP) users [12 COPD and 8 $\mathrm{BA}$. All these patients were on moderate dose of metered dose inhaler MDI of corticosteroids for at least 3 months.

\section{Exclusion criteria}

The following patients are excluded from the study; those who had taken nasal, topical or ocular corticosteroids within the last 3months, patients with any etiological factor that might affect the larynx and the vocal folds e.g.: voice abusers, patients suffering from reflux, or patients who underwent any surgical interventions of the neck or the larynx, smoker patients or patients discontinued smoking less than 6 months prior to screening, and patients with any of the collagen diseases or mediastinal tumors.

\section{Methods}

All patients were conducted to the following protocol; history taking (age, sex, disease duration and type of inhaled steroids), local chest examination, X-ray, CT scan, and Spirometer (to confirm the disease and exclude other chest diseases and exacerbation), general examination (to exclude other organ involvement, comorbidities like gastro esophageal reflux disease and sinusitis, and to assess complications), and Clinical diagnostic aids including videolaryngoscopic examination (to detect VF mobility, presence of local or diffuse congestion, nodules, mucus spills on VF, ventricular fold hypertrophy, glottic gap, VF girth, and vascular marking) and acoustic analysis (measuring Average Pitch, Jitter, Shimmer, and Harmonic to noise $\mathrm{H} / \mathrm{N}$ ratio). Auditory perceptual assessment (APA) using modified GRBAS scale (Grade of dysphonia, Roughness, Breathiness, Asthenia, and Straining) was performed but not statistically analyzed since there was no need for it in the purposes of this study other than a mean of detecting dysphonia presence as well as being an unreliable method of assessment.

Speech material was designed to include a range of tasks that make varying demands on the vocal apparatus. Both sustained phonation of /a/ vowel for 5 seconds duration and connected speech of a phonetically balanced Arabic paragraph for 1 minute were included providing data from which a variety of acoustic measurements could be obtained. This was made at comfortable pitch and loudness. The subjects were given time before the test to familiarize themselves with the connected speech sample. Speech signals were recorded using a pressure-sensitive microphone positioned $45^{\circ}$ degrees with the subject's mouth of a constant distance $10 \mathrm{~cm}$. Acoustic analyses were performed through the Multi-dimensional Voice Program (MDVP). The percentages of jitter, shimmer, and $\mathrm{H} / \mathrm{N}$ ratio were measured for the recorded sustained /a/ sound while average pitch was measured for the recorded paragraph.

\section{Statistics}

SPSS for Windows (vers.16) was used for the statistical analysis. Group differences on categorical data were examined using the Chisquared $\left(\chi^{2}\right)$ and group differences on continuous variables were examined with ANOVAs or the MannWhitney U test (when data was significantly skewed).

\section{Results}

This study was carried on 40patients that had bronchial asthma (BA) 11 females (27.5\%), and 29 males (72.5\%), their ages ranged from 29 to 42 years with a mean age $35.1 \pm 5.3$. BA patients had disease duration that ranged from 2- 8years with mean duration 5.6+3.1 years. The 40 COPD patients were 13 females (32.5\%), and 27 males $(67.5 \%)$ with their ages ranged from 31 to 43 years, having a mean age $32.5 \pm 5.2$. The disease duration in COPD ranged from 4 to 12 years, with mean duration $6.4 \pm 2.8$ years. Table 1 shows demographic and clinical data in both BA and COPD groups that reveals no statistically significant differences in between them as regards patient's age, sex or disease's duration. There was no significant difference $(\mathrm{P}>0.05)$ between bronchial asthma group and the COPD group in the average pitch, the jitter, and shimmer. The harmonic to noise ratio showed significant decrease $(\mathrm{P}>0.05)$ in bronchial asthma group compared to the COPD group (Table 2). 
Table I Demographic and clinical data in Bronchial asthma and COPD patients

\begin{tabular}{|c|c|c|c|c|}
\hline \multirow[b]{2}{*}{ Parameter } & \multirow[b]{2}{*}{ BA } & \multicolumn{3}{|c|}{$X^{2}$} \\
\hline & & COPD & t-test & P-value \\
\hline Female & II (27.5\%) & $13(32.5)$ & & 0.63 \\
\hline Male & 29 (72.5\%) & 27 (67.5\%) & 0.24 & NS \\
\hline Age: Mean $\pm S D$ & $35.1 \pm 5.3$ & $33.5 \pm 5.2$ & & 0.176 \\
\hline Range & $29-42$ & $31-43$ & $1.36^{*}$ & NS \\
\hline Duration & $5.6 \pm 3.1$ & $6.4 \pm 2.8$ & $121^{*}$ & 0.23 \\
\hline 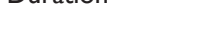 & $2-8$ & $4-12$ & & NS \\
\hline
\end{tabular}

Table 2 The difference in acoustic parameters among both studied groups

\begin{tabular}{|c|c|c|c|c|c|c|c|}
\hline Parameter & Group & No. & Mean & $\mathrm{SD}( \pm)$ & T- value & $P$ - value & Sig. \\
\hline Average & BA & 40 & 196.9 & 16.3 & \multirow{2}{*}{1.64} & \multirow{2}{*}{$>0.05$} & \multirow{2}{*}{ Ns } \\
\hline Pitch & COPD & 40 & 203.8 & 21.1 & & & \\
\hline \multirow{2}{*}{ Jitter } & BA & 40 & 1.0 & 0.14 & \multirow{2}{*}{1.47} & \multirow{2}{*}{$>0.05$} & \multirow{2}{*}{ NS } \\
\hline & COPD & 40 & I.I & 0.17 & & & \\
\hline \multirow{2}{*}{ Shimmer } & BA & 40 & 0.98 & 0.12 & \multirow{2}{*}{0.592} & \multirow{2}{*}{$>0.05$} & \multirow{2}{*}{ NS } \\
\hline & COPD & 40 & 1.005 & 0.12 & & & \\
\hline \multirow{2}{*}{$\mathrm{H} / \mathrm{N}$ ratio } & BA & 40 & 11.9 & 1.14 & \multirow{2}{*}{3.1} & \multirow{2}{*}{$<0.05$} & \multirow{2}{*}{$\mathrm{S}$} \\
\hline & COPD & 40 & 12.9 & 1.8 & & & \\
\hline
\end{tabular}

There was a highly statistically significant difference between cortisone administration regarding Jitter, and H/N ratio. They were different groups of cortisone administration regarding average pitch except between group II and III. While there was a statistically significant difference especially between groups II \& III and IV of cortisone administration regarding Jitter, and $\mathrm{H} / \mathrm{N}$ ratio. They were there was no significant difference between different groups regarding shimmer (Table 3).

Table 3 The relation between acoustic parameters and type of cortisone administered among studied groups

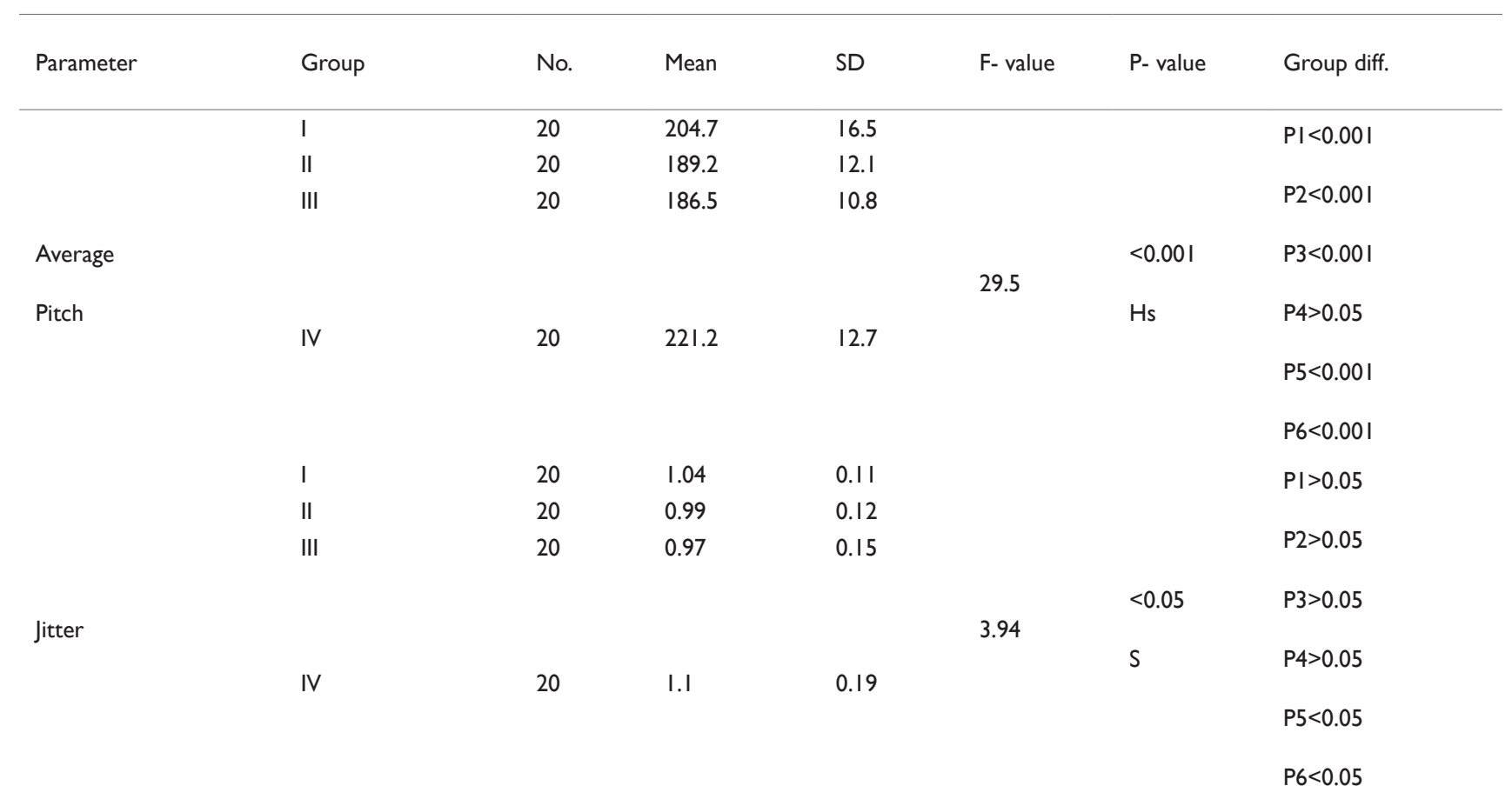


Table continued...

$\begin{array}{lll}\text { I } & 20 & 0.99 \\ \text { II } & 20 & 0.97 \\ \text { III } & 20 & 0.97\end{array}$

$\mathrm{H} / \mathrm{N}$ ratio

Sixty five out of eighty patients were identified who were diagnosed as having steroid inhaler laryngitis (SIL) with laryngoscopic findings during the studied period that evoked this diagnosis with a rate of 2-3 cases per month with a statistically significant difference among the four groups of cortisone regarding laryngoscopic findings, as presence of congestion (diffuse and local), mucus spills on VF, hypertrophy, and presence of glottic gap were all higher in frequency among group used fluticasone propionate, while least signs found among ciclesonide users.

Laryngoscopic changes that seen in patients with SIL range from mild to severe changes. Mild changes include localized and generalized erythema (Figures 1\&2), edema (Figure 3), and presence of mucus spills on VF while moderate ones include mucosal thickening (localized or generalized), hypertrophy, and presence of glottal gap (Figure 4). Leukoplakia, laryngeal or pharyngeal candidiasis, and granulation aren't detected in any of the patients of the four studied groups.

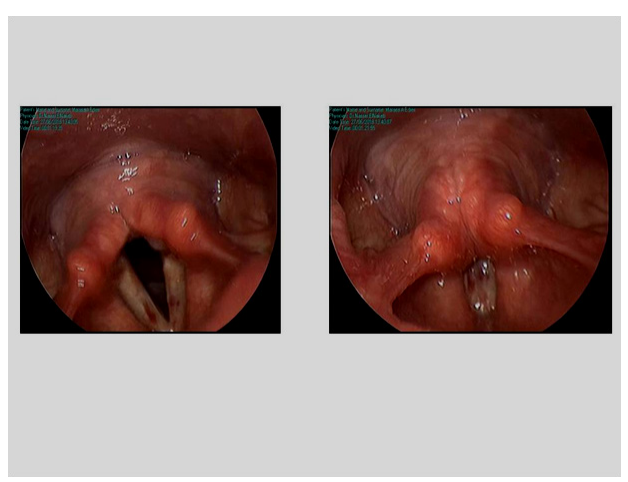

Figure I Direct laryngeal examination via VLS shows localized congestion in both vocal folds.

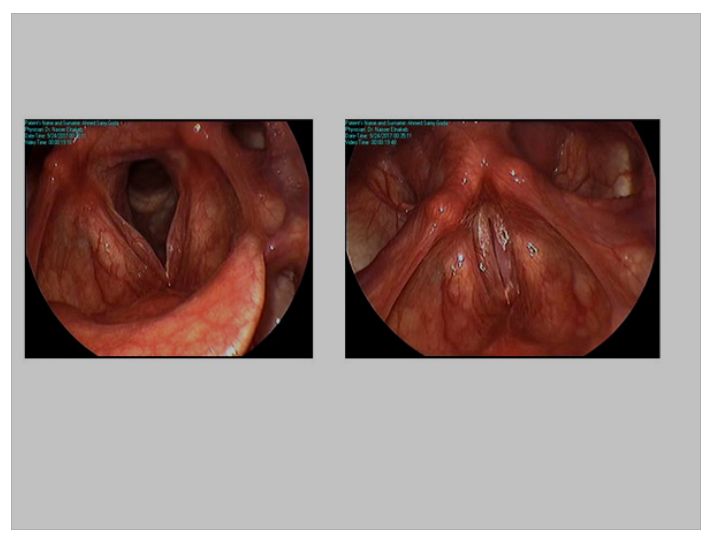

Figure 2 Direct laryngeal examination via VLS shows generalized congestion occupies the whole length of both vocal folds.

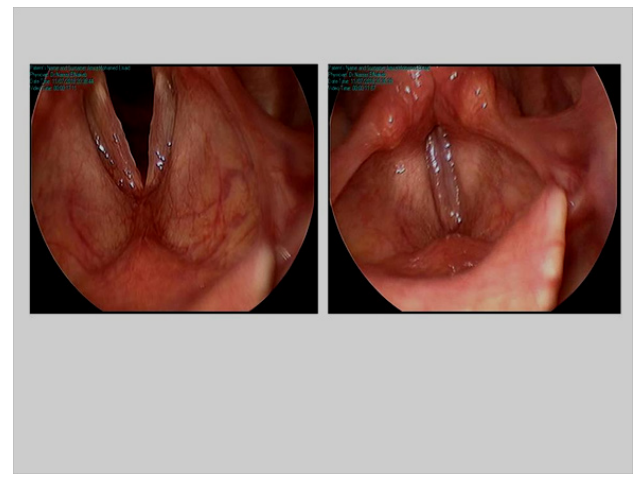

Figure 3 Direct laryngeal examination via VLS shows bilateral mucosal edema in addition to generalized congestion. 


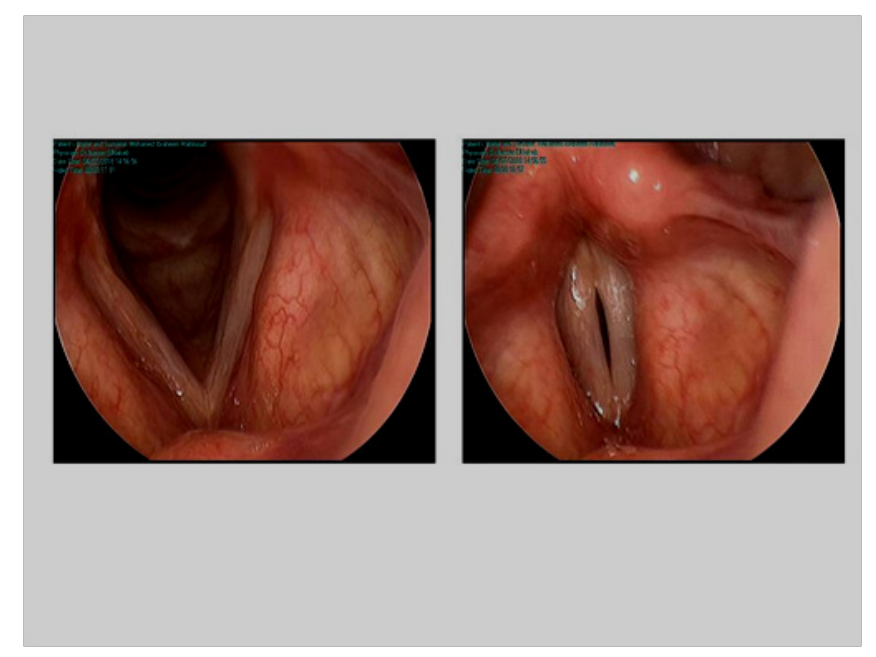

Figure 4 Direct laryngeal examination via VLS shows glottal gap fusiform shaped about Imm at maximal width.

Table 4 The relation between VF examination through laryngoscope and type of cortisone administered in studied patients

\begin{tabular}{|c|c|c|c|c|c|c|}
\hline Vocal Fold (VF) & $\begin{array}{l}\text { G I } \\
\text { No (\%) }\end{array}$ & $\begin{array}{l}\text { G II } \\
\text { No (\%) }\end{array}$ & $\begin{array}{l}\text { G III } \\
\text { No (\%) }\end{array}$ & $\begin{array}{l}\text { G IV } \\
\text { No (\%) }\end{array}$ & $\mathrm{X}^{2}$ & $P$ value \\
\hline Normal cases & $2(10)$ & $2(10)$ & $10(50)$ & I (5) & 17.3 & $<0.05^{*}$ \\
\hline Local congestion & $2(10)$ & $2(10)$ & I (5) & $7(35)$ & 8.6 & $<0.05^{*}$ \\
\hline Diffuse congestion & $0(0.0)$ & 0 & 0 & $3(15)$ & 9.4 & $<0.05^{*}$ \\
\hline Nodules & $0(0.0)$ & I (5) & $0(0.0)$ & $2(10)$ & 3.8 & $>0.05$ \\
\hline VF increased girth & $4(20)$ & $4(20)$ & $2(10)$ & $6(30)$ & 2.5 & $<0.05^{*}$ \\
\hline Increased vascular marking & $0(0.0)$ & I (5) & $0(0.0)$ & $3(15)$ & 6.32 & $>0.05$ \\
\hline mucus spills on VF & I (5) & I (5) & I (5) & $7(35)$ & 12.3 & $<0.05^{*}$ \\
\hline Ventricular fold Hypertrophy & I (5) & $0(0.0)$ & 0 & $3(15)$ & 6.3 & $>0.05$ \\
\hline Glottic gap & $3(15)$ & $4(20)$ & $2(10)$ & $10(50)$ & 10.7 & $<0.05^{*}$ \\
\hline
\end{tabular}

\section{Discussion}

The larynx is a complex organ that includes some of the most intricate structures of the human body. Owing to its delicate nature, it is affected by different medications to varying degrees. Many of these effects manifest in subjective complaints in one's voice or swallow. ${ }^{10}$ Inhaled corticosteroids have an important and well-established role in the treatment of asthmatic and COPD patients whatever their severity. One of the most common side effects of ICS therapy is the irritation of the upper aerodigestive tract. These drugs may have important local side effects, such as dysphonia, candidiasis, pharyngitis, sense of fullness, throat clearing, and cough which tend to occur with all kinds of ICS and it almost related to dose and duration of steroid administration. . $^{7,11}$

Steroid inhaler laryngitis is a kind of chemical laryngopharyngitis, like reflux laryngitis, that is caused by topical steroid administration and causes a series of physical laryngeal findings. The incidence of dysphonia on various steroid inhaled preparations varies from $1 \%$ to $9 \%$ on the time it is $0 \%$ to $3 \%$ for non-steroid inhalers. From all inhaled steroid preparations fluticasone propionate has the most effective action with greater topical potency, tissue retention and halflife. ${ }^{5}$ In the current study, there was no significant difference between bronchial asthma and COPD patients as regards average pitch, the jitter and shimmer $(\mathrm{P}>0.05)$ while the harmonic to noise ratio showed significant decrease in bronchial asthma group compared to the COPD group $(\mathrm{P}>0.05)$. Saeed et al., ${ }^{12}$ found that there was no significant difference between bronchial asthma and COPD patients as regards Shimmer while there was significant difference as regards average pitch, the jitter and the harmonic to noise ratio $(\mathrm{P}>0.001)$. Almaraghy et al., ${ }^{13}$ found that the variables of acoustic analysis, that are jitter and shimmer, increased than normal range. These significantly affected acoustic parameters could be explained by the fact that the oscillating character and mechanical properties of the vibratory edges of the vocal folds are affected by the resultant pathological effects such as irregularities in the free edge of vocal folds and congestion. These structural changes could lead to disruptive mechanical effects, an abnormal vibratory pattern, asymmetry in vocal fold vibration, and tissue properties with a subsequent affection of the acoustic parameters. It was reported by Kotby, ${ }^{14}$ that any subtle deviation of acoustic parameters may affect the pathological changes in voice. 
The source of increased jitter and shimmer lies in a combination of anatomical and physiological changes in the vocal folds. An increase in the vocal fold mass and/or reduced stiffness of the cover is considered the most plausible causes of this change. Jitter is considered to reflect the stability of vocal fold vibration, whereas shimmer is thought to be related to the regularity of vocal fold contact. It is thus plausible that edema interferes with the adequacy and consistency of contact between the vocal fold edges during phonation, which would result in increased shimmer values in smokers. The values obtained for $\mathrm{H} / \mathrm{N}$ ratio were attributed by Shastry et al., ${ }^{15}$ to increased breathiness in the voice due to reduced subglottic pressure built up below the vocal folds of individuals with COPD, because of which presence of noise in the spectrum was higher in them.

Hanania et al., ${ }^{16}$ reported that these findings could be explained by the irritation of the laryngeal mucosa or by deposits from the inhalation of steroids. These results were similar to the findings of Souza et al., ${ }^{17}$ who showed that voice pathology associated with ICS can cause increased noise components in the voice signal such as fundamental frequency, turbulent noise, and voice breaks. Roland et al., ${ }^{18}$ in their study on the impact of ICS on voice, found an increased incidence of frequency and amplitude perturbation values (jitter and shimmer) in patients who received ICS in high doses and for a long duration. In the present study although acoustic parameters' values in SIL patients are all altered with significant relations when compared them with standard values of normal population, ${ }^{19}$ but it had no statistical significant differences except for $\mathrm{H} / \mathrm{N}$ ratio which showed significant relation on comparing its results between BA and COPD groups. On the other hand: There was a statistically significant difference between group III and IV of cortisone administration regarding average pitch, Jitter, and $\mathrm{H} / \mathrm{N}$ ratio. They were more worse in group IV when compared to group III. While there was no significant difference between the two groups regarding shimmer.

In disagreement with our study, Shaw and Edmunds ${ }^{20}$ found that dysphonia not to be a problem when using regular inhaled BDP 100-1500 lg per day although no objective measure of dysphonia was used. In the present study, there was statistically significant difference among four groups of cortisone regarding laryngoscopic findings, as presence of congestion (diffuse and local), mucus spills on VF, and presence of glottic gap that were all higher in frequency among group used fluticasone propionate, while least signs found among ciclesonide users. This came in agreement with other studies that have reported an increased risk of dysphonia and voice changes with the use of fluticasone propionate compared to beclomethasone dipropionate (BDP). It has been suggested that the etiology of dysphonia in some cases is due to a steroid myopathy affecting the vocal fold muscles (creating glottal gap). A closer examination using flexible laryngoscopy and videostroboscopy reveals varying degrees of myopathy in symptomatic patients. This problem can, however, be reversed when therapy with the inhaled steroid is stopped. ${ }^{21-23}$

This can also be explained by that fluticasone propionate is inhaled in its pharmacologically active form, whereas ciclesonide is inhaled as inactive compounds and are converted by lung esterases to its active metabolites. For example, ciclesonide is a parent compound that is converted to the active metabolite desisobutyryl-ciclesonide (des-CIC) by the lungs' esterases. The lack of esterases, practically, in the area of the laryngopharynx, minimizes the incidence of local side effects of the product in this area. ${ }^{24,25}$ This can explain why ciclesonide and beclomethasone dipropionate are associated with the lowest dysphonia prevalence. As we found that patients under fluticasone propionate inhalation therapy have the major and most common laryngeal findings that was explained by Lavy et al., ${ }^{7}$ and Roland et al., ${ }^{18}$ who stated that these prominent mucosal changes was attributable to fluticasone's greater potency and tissue affinity.

The presence of congestion (diffuse and local) with ICS, was previously reported by Muzeyyen et al., ${ }^{26}$ who explained it mainly by tissue reaction and fluid accumulation due to irritation, by inhaled steroids. Chronic cough, throat clearing, allergens and release of inflammatory mediators as histamine may also cause congestion and fluid accumulation. Vocal fold nodules and ventricular fold hyper trophy, are presented as a concomitant or secondary signs, may be caused by vocal abuse resulting from chronic cough as previously reported by John et al. ${ }^{27}$ Viveka et al., ${ }^{28}$ detected laryngeal findings including edema, ventricular hypertrophy in $30 \%$ of bronchial asthma patients with long term therapy. In this study, the ventricular bands hypertrophy could be explained on the basis of the long standing chronic cough and straining of the ventricular folds. The tendency of some patients to compensate by phonatory hyperfunctional element might lead to more ventricular band hyperactivity.

\section{Conclusion}

Obstructive lung disease patients may suffer from voice problems related to the type of inhaled corticosteroids. So, regular laryngeal examination in those patients is important. Steroid inhaler laryngitis is a form of chemical laryngitis induced by topical steroid administration. Local side effects, particularly dysphonia/change of voice character, are dependent on the type of inhaled corticosteroids. Fluticasone propionate containing ICS was the most frequently prescribed and was the most common cause of dysphonia, vocal fold abnormalities, and steroid inhaler laryngitis while least local side effects found among ciclesonide users. Patients receiving inhaled corticosteroids should be adequately informed about the possibility of voice changes as a result of this treatment. It should be clear for chest doctors, otolaryngologists, and phoniatricians to address the symptoms and laryngeal signs as a result of the use of inhaled corticosteroids, their impacts on patients' voice, and the possibility of reversibility of these manifestations after the end of cortisone use. Chest doctors are advised to avoid the use of fluticasone propionate preparation if its therapeutic effect could be achieved by another alternative safe product especially when treating those who are professional voice users. These results to be subjected to their researches.

\section{Ethical consideration}

The study protocol was approved by the Research Ethics committee of Menoufia University.

\section{Discloser statement}

The authors have no conflicts of interest to declare.

\section{Author contribution}

All authors had nearly equal participations in this study.

\section{Acknowledgements}

We would like to express our deepest thanks to all subjects for their cooperation and the associates who helped within the work. In addition to providing our appreciation to Menoufia and Zagazig University Hospitals where the study conducted. 


\section{Conflicts of interest}

No conflicts of interest declared.

\section{Funding details}

This research was carried out without funding.

\section{References}

1. Raherison, C, Girodet PO. Epidemiology of COPD. Eur Respir Rev. 2009; 18(114):213-221.

2. Greenberger PA, Grammer LC. Pulmonary disorders, including vocal cord dysfunction. J Allergy Clin Immunol. 2010;125(2): S248-S254.

3. Gater A, Nelsen L, Fleming S, et al. Assessing asthma symptoms in adolescents and adults: Qualitative research supporting development of the asthma daily symptom diary. Value in Health. 2016;19(4):440-450.

4. Ihre E, Zetterström O, Ihre E, et al. Voice problems as side effects of inhaled corticosteroids in asthma patients-aprevalence study. $J$ Voice. 2004;18(3):403-414.

5. Del Gaudio JM. Steroid inhaler laryngitis: dysphonia caused by inhaled fluticasone therapy. Arch Otolaryngol Head Neck Surg. 2002;128(6):677681.

6. Nishimura K, Koyama H, Ikeda A, et al. The effect of high-dose inhaled beclomethasone dipropionate in patients with stable COPD. Chest. 1999;115(1):31-37.

7. Lavy JA, Wood G, Rubin JS, et al. Dysphonia associated with inhaled steroids. J Voice. 2000;14(4):581-588.

8. Mirza N, Kasper Schwartz S, Antin Ozerkis D. Laryngeal findings in users of combination corticosteroid and bronchodilator therapy. Laryngoscope. 2004;114(9):1566-1569.

9. Acar GO, Adatepe NU, Kaytaz A, et al. Evaluation of laryngeal findings in users of inhaled steroids. Eur Arch Otorhinolaryngol. 2010;267(6):917923.

10. Harounian J, Postevka E, Jamal N. Medications and the larynx. Current Opinion in Otolaryngology \& Head and Neck Surgery.| 2019.

11. Chmielewska M, Akst LM. Dysphonia associated with the use of inhaled corticosteroids. Curr Opin Otolaryngol Head Neck Surg. 2015;23(3):255259 .

12. Saeed AM, Riad NM, Osman NM, et al. Study of voice disorders in patients with bronchial asthma and chronic obstructive pulmonary disease. Egyptian Journal of Bronchology. 2018;12(1):20.

13. Almaraghy AA, Seliem A, Khalifa RA. Studying the effect of inhaled corticosteroids on the larynx in bronchial asthma patients using videostroboscopy. The Egyptian Journal of Otolaryngology. 2012;28(3):270.

14. Kotby MN. Voice disorders: recent diagnostic advances. Egypt $J$ Otolaryngol. 1986;3(10):69-98.
15. Shastry A, Balasubramanium RK, Acharya PR. Voice related quality of life in individuals with chronic obstructive pulmonary disease. International Journal of Medical Research \& Health Sciences. 2015;4(1):110-117.

16. Hanania NA, Chapman KR, Kesten S. Adverse effects of inhaled corticosteroids. Am J Med. 1995;98(2):196-208.

17. Souza AM, Duprat VD, Costa ADC, et al. Use of inhaled versus oral steroids for acute dysphonia. Braz J Otorhinolaryngol. 2013;79(2):196202.

18. Roland NJ, Bhalla RK, Earis J. The local side effects of inhaled corticosteroids: current understanding and review of the literature. Chest. 2004;126(1):213-219.

19. Lathad Evi HT, Guggarigoudar SP. Objective Acoustic Analysis and Comparison of Normal and Abnormal Voices. Journal of Clinical \& Diagnostic Research. 2018;12(12):1-4.

20. Shaw NJ, Edmunds AT. Inhaled beclomethasone and oral candidiasis. Arch Dis Child. 1986;61(8):788-790.

21. Fabbri L, Burge PS, Croonenborgh L, et al. Comparison of fluticasone propionate with beclomethasone dipropionate in moderate to severe asthma treated for one year. International Study Group. Thorax. 1993;48(8):817-823.

22. Selroos O, Backman R, Forsén KO, et al. Local side-effects during 4-year treatment with inhaled corticosteroids-a com between pressurized metered-dose in and Turbuhaler®. Allergy. 1994;49(10):888-890.

23. Ayres JG, Bateman ED, Lundback B, et al. High dose fluticasone propionate, $1 \mathrm{mg}$ daily, versus fluticasone propionate, $2 \mathrm{mg}$ daily, or budesonide, $1.6 \mathrm{mg}$ daily, in patients with chronic severe asthma. International Study Group. Eur Respir J. 1995;8(4):579-586.

24. Nave R, Zech K, Bethke TD. Lower oropharyngeal deposition of inhaled ciclesonide via hydrofluoroalkane metered-dose inhaler compared with budesonide via chlorofluorocarbon metered-dose inhaler in healthy subjects. Eur J Clin Pharmacol. 2005;61(3):203-208.

25. Buhl R. Local oropharyngeal side effects of inhaled corticosteroids in patients with asthma. Allergy. 2006;61(5):518-526.

26. Muzeyyen D, Emel E, Ismail K, Turgay C, et al. Subjective and bjective Evaluation of the Voice Quality in Patients With Asthma. $J$ Voice. 2005;10:1016.

27. Jones PW, Willis LR, Burge PS, et al. Disease severity and the effect of fluticasone propionate on chronic obstructive pulmonary disease exacerbations. Eur Respir J. 2003:21(1):68-73.

28. Viveka Lyberg Ahlander, Lucyna Schalen, Marika Habbe, et al. Vocal Function in Relation to Inhalatory Steroid Therapy in Patients with Asthma. Department of Logopedics, Phoniatrics and Audiology, University Hospital of Lund. The Voice Foundation. Journal of Voice, 2002; pp. 60-72. 